\title{
Non-Host Organism Identifiers Supplemental Qualifiers Dataset
}

National Cancer Institute

\section{Source}

National Cancer Institute. Non-Host Organism Identifiers Supplemental Qualifiers

Dataset. NCI Thesaurus. Code C147230.

A dataset containing supplemental information, specifically non-standard variables, to parent records in the non-host organism identifiers domain. 